\title{
A Bildung e a instituição escolar: o modelo hegeliano de escola
}

\author{
Marcos Fábio Alexandre Nicolau ${ }^{1}$
}

\begin{abstract}
Resumo
Em seus Gymnasialreden (1808-1815), Hegel afirma ser a formação cultural (Bildung) o resultado do processo de desenvolvimento do homem, mas enfatiza a necessidade da mediação de umateoria da educação(Erziehung), a ser realizada nas instituições escolares, como fundamento desse processo. O presente artigo pretende enunciar quais elementos a instituição escolar deve possuir para realizar esse processo formativo a partir da análise dos discursos erigidos pelo filósofo como reitor e professor do Ginásio de Nüremberg. A relevância da educação escolar no processo de formação do homem é evidenciada por Hegel em seus discursos, justificando-a como momento mediador entre a saída da vida familiar e a entrada na sociedade civil.
\end{abstract}

Palavras-chave: Escola; Formação cultural; Sistema hegeliano.

\section{Bildung y la institución escolar: el modelo hegeliano la escuela}

\section{Resumen}

En sus Gymnasialreden (1808-1815), Hegel afirma ser la formación cultural (Bildung) el resultado del proceso de desarrollo del hombre, pero enfatiza la necesidad de la mediación de una teoría de la educación (Erziehung), que se celebrará en las escuelas, como el fundamento de este proceso. Este artículo pretende explicar qué elementos la institución escolar debe poseer para realizar este proceso formativo a partir del análisis de los discursos construidos por el filósofo como rector y profesor en el Gimnasio de Nüremberg. La relevancia de la educación escolar en el proceso de formación del hombre se evidencia por Hegel en sus discursos, justificándolo como momento mediador entre la salida de la vida familiar y la entrada en la sociedad civil.

Palabras claves: Escuela; Formación cultural; Sistema hegeliano.

\footnotetext{
1 Doutor em Educação pela Universidade Federal do Ceará - UFC. Professor do Curso de Filosofia e Colaborador do Mestrado Profissional em Saúde da Família da Universidade Estadual Vale do Acaraú - UVA. Coordenador do Laboratório de Estudos Hegelianos LEH/UVA. Membro do Grupo de Pesquisas em Filosofia da Religião - GEPHIR-UVA/CNPq e do Grupo de Estudo e Pesquisa em Ensino de Filosofia - GEPEFIL/UVA. E-mail: marcosmcj@yahoo.com.br
} 
Em discurso proferido em 1809, por ocasião do fim de seu primeiro ano à frente do Ginásio de Nüremberg, Hegel afirmara que o bom funcionamento dos povos pressuporia dois ramos primordiais: 1. uma boa administração da justiça e, 2. bons estabelecimentos de ensino, pois, segundo Hegel, "não há outros cujas vantagens e os efeitos o homem privado dê conta e sinta de forma tão imediata, próxima a pormenorizada" (HEGEL, 1994, p. 27), o que complementa mais tarde em outro discurso afirmando que:

Os tesouros interiores que os pais dão aos filhos, através de uma boa educação e pela utilização de estabelecimentos de ensino, são indestrutiveis, e mantém o seu valor em todas as circunstâncias; é o melhor e mais seguro bem que podem proporcionar e deixar aos filhos (HEGEL, 1994, p. 76).

Em lena, Hegel já refletiu sobre uma educação vinculada a vida ética dos povos, de forma que em seu artigo Sobre as Maneiras Científicas de tratar o Direito Natural (Über die wissenschaft Behandllungsarten des Naturrechts), de 1802, já anunciara ser a criança, indiscutivelmente o principal sujeito da educação, pois representaria "a forma da possibilidade de um indivíduo ético" (HEGEL, 2007, p. 110), demarcando o vínculo da educação com a vida pública.

Uma educação vinculada a vida ética implica na estruturação de uma sociedade de cidadãos conscientes e participantes, o que o filósofo expõe nos seguintes termos:

A respeito da educação, [é o que] um pitagórico respondeu, quando alguém lhe perguntou qual seria a melhor educação para seus filhos: "É que tu faças dele um cidadão de um povo bem organizado" (HEGEL, 2007, p. 111; Cf. HEGEL, 2010, p. 172).

A proposta hegeliana de uma educação para a cidadania perpassa toda sua obra, que tem como culminância a vida ética (Cf. PERTILLE, 2005, 190), efetivada nos conceitos de Sociedade Civil e de Estado; e, como já fora mencionado anteriormente, opõe-se a proposta original de Rousseau, no Emílio ou da Educação, pois Hegel atribui a educação o objetivo de superar o estado natural, vinculado a esfera da Família, abrindo-se a vida cultural e suas instâncias. Apenas uma teoria da educação que objetiva efetivar os ideais da formação cultural (Bildung) pode fazer do homem o que ele deve ser: um ser que se realiza no 
ultrapassar do natural para o cultural, ou para o ético. Por isso, uma das principais preocupações deve ser a formulação de um modelo de escola apropriado a esse projeto. Hegel afirmara que "A escola encontra-se, de fato, entre a família e o mundo efetivo e constitui o elemento mediador de ligação, de passagem daquela para este" (HEGEL, 1994, p. 61).

Note-se que essa formação é uma tarefa universal, pois faz parte da própria condição humana, no entanto uma teoria da educação é algo que ocorre dentro de um sistema escolar, formatado a partir das escolhas que um governo assume na gerência de suas instituições escolares. Pensar um modelo de escola² que possibilite a formação cultural dos indivíduos é tarefa do Estado, que deve conformar o mesmo não apenas a "uma palavra", ou a uma teoria abstrata sem vinculações com a realidade cultural, como advertira Herder, mas a realidade de seu povo, o que implica na consideração de elementos históricos, sociais, linguísticos, econômicos, geográficos, climáticos, etc. (Cf. HERDER, 1995, p. 35).

A figura de Herder é aqui essencial, pois com sua compreensão de que um povo possui uma identidade cultural única forneceu aos pensadores do século XIX as bases para um historiocentrismo, do qual Hegel é um dos principais herdeiros. Isso permite compreender porque Hegel reconhecia o governo prussiano como responsável pelo "aperfeiçoamento das escolas alemãs": para o filósofo, na medida em que o governo assume a proposta de reforma, leva em consideração as especificidades da realidade de seu povo, principalmente em sua perspectiva institucional, e não apenas teórica, formulando um modelo de escola centrado na formação humanística, progredindo do particular ao universal, esse mesmo governo opta pela efetivação do projeto universal da formação cultural e, consequentemente, da vida ética.

A busca pela efetivação desses ideais fora declarada no discurso proferido em 1809, no qual o filósofo aproveita o fato do recém-criado Ginásio de Nüremberg

\footnotetext{
2 Quando discuto um "modelo de escola", tenho em foco um modelo que vá além de sua concepção arquitetônica. Assim como Young (2007) considero necessário a esse modelo o esclarecimento de três questões: 1) quais os propósitos desse modelo de escola; 2) como esse modelo de escola pretende dar aos alunos o "conhecimento poderoso", ao qual eles raramente terão em casa; e 3) como esse modelo de escola estabelecerá a diferenciação entre conhecimento escolar e o não-escolar.
} 
ter completado seu primeiro ciclo escolar em sua gestão. Hegel analisa como se deu a participação do estabelecimento no sistema educacional prussiano, em seus avanços e dificuldades, pois "Porque a própria coisa acaba de nascer, a sua substância ocupa ainda a curiosidade e as considerações mais reflexivas" (HEGEL, 1994, p. 28).

A questão que o discurso hegeliano de 1809 suscita é a formatação de um modelo de escola que possibilite ao indivíduo as bases fundamentais para o autocultivo próprio da formação cultural, ainda que reconheça o caráter parcial da formação escolar, configurando um dos momentos da formação humana proposta pelo filósofo, já que "O juízo proferido pela escola não pode, tão pouco, ser algo de acabado quanto o homem nela não está acabado" (HEGEL, 1994, p. 65).

Por isso, depois de um breve comentário acerca do convite "para apresentar em um discurso a história do Ginásio no passado ano e mencionar aquilo que seja adequado para relação do público com o mesmo", Hegel aponta alguns elementos acerca da vantagem reconhecida de uma "nova instituição escolar", favorecida pela "necessidade de modificação" (HEGEL, 1994, p. 27).

O "novo estabelecimento", alude Hegel, não abriu mão da historia dos estabelecimentos de ensino precedentes, evitando assim o risco de tornar-se algo "passageiro" e "experimental", pois aproveitou das experiências passadas para consolidar seus ideais. Hegel expõe no discurso de 1809 algumas "idéias gerais" provenientes de sua vivência, ou seja, das "múltiplas atividades" exercidas por seu cargo nesse período. O trabalho realizado no Ginásio de Nüremberg não configura, dessa forma, um espaço para o teste de teorias educacionais, mas sim para a consolidação da proposta neohumanista de reforma educacional assumida por Hegel. Eis uma postura importante para que a instituição escolar constitua-se como momento efetivo da formação cultural: não ser uma experiência, mas sim a objetivação de uma estrutura previamente pensada.

Ela não pode ser o momento da formulação de uma teoria da educação, mas de sua realização. Uma teoria da educação pode ser vislumbrada em duas perspectivas fundamentais: sua formulação e sua aplicação. É obvio que pensar a 
formulação de uma teoria implica em um processo de elaboração, ampliação e revisão contínuos 3 , mas desse processo sempre deve derivar uma teoria aplicável, que garanta o ensino-aprendizagem. Por isso, Hegel constata em seu discurso que a instituição escolar possui um pressuposto irrenunciável:

A instalação de uma instituição está concluída antes de ter formado o seu tom e espírito; mas é igualmente essencial para a sua completude que aquilo que, de início, é o seguimento de uma ordem, se torne num hábito e que se forme e fixe uma atitude interior uniforme (HEGEL, 1994, p. 42).

No entanto, para o filósofo tal modelo deveria cumprir com aquilo que entende como sendo a função da escola nesse projeto, que pode ser dividida nas três esferas responsáveis diretamente pela concretização do ideal da formação cultural:

1. A instituição escolar deve proporcionar a todos a educação, ou seja, deve zelar pelo princípio de publicidade do saber, eis seu propósito. Todos devem receber os meios para aprender o que the é essencial como homens e o que thes é útil para sua condição social (Cf. HEGEL, 1994, p. 30), ou seja, o ideal de uma educação para todos, tão em voga no cenário pós-revolução francesa, permanece latente no pensamento pedagógico hegeliano. ${ }^{4} \mathrm{~A}$ escola, assim, assume uma função social de extrema importância, pois está a serviço daqueles "que até agora sentiram a falta de algo melhor" (HEGEL, 1994, p. 30).

Dessa forma a escola pode ser considerada corresponsável pela estruturação social do Estado - o que em Hegel significa a efetivação de um estado ético -, pois, como dirá em seu discurso proferido em 1811, é ela responsável

3 Cabe salientar que os momentos de ampliação e revisão são recorrentes na constante reelaboração de um modelo escolar. A instituição escolar nunca deve ser algo estático, pois deve educar o indivíduo para agir sobre sua realidade em constante atualização, já que, segundo Hegel, o indivíduo em formação sempre será filho de seu tempo. (Cf. HEGEL, 2010, p. 43).

${ }^{4}$ É nítida a relação do discurso hegeliano com a proposta de Condorcet, que descrevera em suas Cinco Memórias sobre a Instrução Pública esse ideal: "A instrução pública é um dever da sociedade para com os cidadãos. [...] As leis pronunciam a igualdade de direitos. Só as instituições de instrução podem tornar essa igualdade real. Aquela que é fixada pelas leis é ordenada pela justiça; mas somente a instrução pode fazer que esse princípio de justiça não fique em contradição com aquele que prescreve não atribuir aos homens a não ser os direitos cujo exercício, conforme a razão e o interesse comum, não firam os direitos de outros membros da mesma sociedade." (CONDORCET, 2008, p. 17 e 37). 
pela qualificação dos funcionários públicos, logo pelo efetivar da ideia de Estado na realidade social - Condorcet complementaria afirmando que "O país mais livre é aquele no qual o maior número de funções públicas pode ser exercido por aqueles que só receberam uma instrução comum" (CONDORCET, 2008, p. 36), ou seja, o país no qual a educação fundamental seria fornecida a todos e os capacitaria á participação política e social, ou, como Hegel argumenta, formaria para as "relações efetivas":

A escola não fica apenas por este efeito geral; ela é também um estado ético particular em que o homem se demora e no qual adquire uma formação prática, habituando-se a relações efetivas. É uma esfera que tem uma matéria e um objeto próprios, os seus castigos e recompensas e que constitui, efetivamente, um degrau essencial no desenvolvimento do caráter ético no seu todo (HEGEL, 1994, p. 61).

2. Essa primeira função escolar seria corroborada por uma segunda: a garantia do ensino das "ciências e a consecução de habilidades e práticas mais elevadas" aos indivíduos em formação. Caberia à escola a formação científica que cada cidadão deve aprender para sua efetiva participação na vida social. Note-se que nem todos chegarão ao ensino superior, mas a formação ginasial deve garantir a todos as bases necessárias para tal, ou seja, deve garantir uma formação básica sólida que garanta aos indivíduos oportunidades de crescimento e participação, proporcionando ao indivíduo em formação a obtenção de "conhecimento poderoso" (Cf. YOUNG, 2007, p. 1294), raramente fornecido em casa.

Alguns poderiam criticar a universalidade dessa função da escola, assim como sua legitimidade, já que a um desinteresse natural da juventude para com o conhecimento científico do currículo escolar, abrindo espaço para questionar a necessidade e a validade da "imposição" desses saberes e valores ao individuo em formação. Contra esse argumento, rechaçado veementemente pelo filósofo, argumenta-se que

Se a teoria abstrata da ciência parece não se relacionar bem com a frescura concreta da jovem plenitude de vida, em contrapartida, o homem apercebeu-se do que é apenas sonho e brilho da vida e do que é a sua verdade; ele experimentou que são os tesouros da sabedoria antiga, cedo implantados no seu coração, que nos sustentam em toda a mudança de circunstâncias, que nos fortalecem e suportam; ele experimentou como é grande o valor da 
cultura em geral, tão grande que um antigo diria que a diferença entre um homem culto e um inculto é tão grande como a diferença entre o homem em geral e uma pedra (HEGEL, 1994, p. 22-23).

Encontra-se aqui a crença hegeliana de que a ciência não está desvinculada da vida, motivo pelo qual todo cidadão deve dominar-lhe as bases. Na Fenomenologia do Espírito, Hegel já havia informado que a ciência é algo próprio do homem, logo acessível a todos, o que faz o ensino das ciências na escola um dos momentos vitais de uma teoria da educação, logo de um modelo de escola. Nela os indivíduos serão apresentados à ciência.

3. Por fim, a conservação do "estudo das línguas antigas" garantirá essa apreensão, estabelecendo a necessária diferenciação entre saber escolar e nãoescolar - embora essa seja uma função específica da instituição ginasial da qual Hegel era reitor, o filósofo dá-lhe status universal. Para o filósofo a formulação de um currículo escolar deve oferecer aos educandos a possibilidade de apreender os fundamentos e desenvolvimentos do espírito absoluto, o que remonta a uma apreensão da cultura greco-romana, na qual a ciência ocidental fixou suas bases. Dessa forma, a escola seria o local onde os indivíduos poderiam estabelecer o contato com tais fundamentos, a partir do estudo das línguas clássicas. Mais adiante, em um tópico específico desse capítulo da tese, analisarei a defesa hegeliana do estudo das línguas clássicas nos discursos, por ser esse um dos pontos principais da proposta neohumanista assumida por Hegel.

Antes, cabe compreender como Hegel pensava ser possível assegurar que a escola cumprisse com tais funções, começando por sua responsabilidade de fornecer o ensino básico a todos. No entanto, cabe salientar que essa não era nem de longe a realidade alemã no XIX. Kant já havia denunciado em suas lições Sobre Pedagogia (Über Pädagogik), ministradas entre os anos de 1776 a 1787, o diminuto número de Institutos de Educação, assim como de alunos nos mesmos. Segundo o filósofo, tais institutos,

Na verdade, são caríssimos e a simples montagem desses colégios acarreta grandes despesas [...] Os edifícios necessários, o pagamento dos diretores, dos supervisores e dos serviçais, absorvem metade do orçamento [...] Por isso também é difícil conseguir que outras crianças, que não as dos ricos, participem nesses institutos (KANT, 1996, p. 30-31). 
O relato kantiano diz respeito ao caráter seletivo que a educação institucional alemã possuía na virada do século XVIII ao XIX, e demonstra a consciência dos pensadores quanto às condições materiais a serem enfrentadas para uma reforma no sistema de ensino. Para Alves (2005, p. 94-95), a denúncia de Kant evidencia uma insuficiência da educação doméstica (família), que por sua vez seria suprida pelos Institutos de Educação, dedicados a essa função complementar, mas o alto custo de manutenção desses estabelecimentos restringia drasticamente seu acesso às camadas mais pobres do povo alemão.

Hegel não ficou alheio a essa realidade nos discursos, reconhecendo que "ainda há muito a desejar e a fazer, e que os males de que as escolas elementares [...] padecem são incuráveis sem uma transformação no essencial" (HEGEL, 1994, p. 82). Nesse ínterim, nos discursos de 1811 e 1815, o filósofo apresentou algumas iniciativas que já estavam em trânsito durante sua gestão no Ginásio de Nüremberg: além de receber auxílios governamentais provindos dos impostos, o estabelecimento recebia doações filantrópicas que seriam voltadas tanto para manutenção e formação de acervos e instalações, quanto para formação de um fundo destinado ao apoio dos alunos necessitados:

É de citar que o fundo destinado ao apoio dos alunos necessitados do Ginásio e do estabelecimento de ensino prático ganhou consistência e segura continuidade quanto à entrada permanente de verbas [...] Este ano as bolsas provenientes daquele fundo [...] foram concedidas e pagas aos alunos do Ginásio [...] Além disso, foram utilizados [...] na distribuição de livros e material escolar. A utilização adequada, a saber, em alunos verdadeiramente necessitados, vocacionados para o estudo, tornou possível uma ajuda mais considerável do que até aqui (HEGEL, 1994, p. 69).

Segundo Alves (2005, p. 109), em torno de uma dezena de estudantes necessitados foram beneficiados por esse fundo, o que em uma escala municipal não representa quase nada, mas ratifica a postura hegeliana de um modelo de escola que conceda, ou pelo menos busque conceder, a todos a educação fundamental necessária à consecução da formação cultural. Dessa forma, o modelo de instituição escolar pensado por Hegel deveria, em sua essência, ser um 
espaço público, aberto as diversas camadas da população, que proporcionasse um momento mediador entre família e sociedade civil aos indivíduos em formação.

No entanto, para que isso ocorresse, dever-se-ia conformar esse espaço a um momento de mediação, ou seja, se o objetivo seria preparar o educando para a vivência da formação cultural, um modelo escolar que assegurasse uma educação para a ciência e para a autonomia seria necessário. A segunda função a ser desempenhada pela instituição escolar, segundo Hegel, incorre na configuração de um espaço escolar de ampla liberdade intelectual no ensino, no qual a comunidade escolar possibilita aos diversos campos do saber o desenvolvimento de suas pesquisas e seu ensino:

O autêntico sinal da liberdade e da força de uma organização consiste em que os diferentes momentos que ela contém se aprofundam em si e perfazem sistemas completos, exercem a sua atividade e vêem-se exercê-la sem inveja e sem receio, e em todos são, por sua vez, partes de um grande todo (HEGEL, 1994, p. 31).

A harmonia proposta por Hegel aos momentos que constituem a escola nos dá uma boa visão do Hegel reitor/administrador, além de evidenciar sua leitura dialética da realidade. Cada ciência teria seu espaço garantido no ambiente escolar, desde que nunca esqueça que é parte de um todo. Da mesma forma, cada setor administrativo, cada função escolar, cada indivíduo da comunidade escolar, possui sua importância no grande conjunto que é a escola. A escola traz em si as marcas de uma realidade contraditória e complexa, pois configura, enquanto instituição histórico-cultural, a objetivação da ideia lógica, o Espírito Absoluto objetivado enquanto instituição.

Dessa forma a escola demarcará o momento do amadurecimento da criança, já que no âmbito familiar a criança age a partir de obediência pessoal motivada pelo amor, enquanto que no âmbito escolar seu comportamento passa a ser regido segundo o dever e a lei - o que será analisado a seguir ao analisar a profissão docente. O indivíduo em formação é estimulado a realizar a necessária passagem do singular ao universal, aqui representado pela comunidade de educandos, no qual aprenderá a respeitar aos outros, que de início lhe são estranhos, mas nem por isso detentores de menor respeitabilidade e confiança. 
A escola é, portanto, a esfera mediadora que faz passar o homem do círculo familiar para o mundo, das relações naturais do sentimento e da inclinação para o elemento da coisa. Isto é, na escola começa a atividade da criança a receber, no essencial e de forma radical, um significado sério, na medida em que deixa de estar ao critério do arbítrio e do acaso, do prazer e da inclinação do momento; aprende a determinar o seu agir segundo uma finalidade e segundo regras; cessa de valer pela pessoa imediata e começa a valer por aquilo que realiza, a conquistar para si um mérito (HEGEL, 1994, p. 61).

Para Hegel, esse momento escolar possibilitará ao educando "ganhar a confiança em si mesmo na sua relação com eles - os outros educando -, e, deste modo, a iniciar-se na formação e na prática das virtudes sociais" (HEGEL, 1994, p. 62). A escola seria então o ambiente no qual o indivíduo em formação adentraria na estrutura sócio-lógica do mundo efetivo:

a escola tem uma relação com o mundo efetivo, e a sua tarefa é preparar a juventude para o mesmo. O mundo efetivo é um todo consistente, ligado em si mesmo, de leis de organizações tendo como fim o universal. Os indivíduos só valem na medida em que se adéquam a este universal e agem em conformidade com ele, e esse mundo não se ocupa dos seus fins, opiniões e mentalidades particulares (HEGEL, 1994, p. 64).

No entanto, o filósofo não cairá no erro de pôr na interação social o propósito principal da escola, pois centra suas atenções na dialética-dialógica das ciências ou disciplinas curriculares que fornecem o conteúdo necessário a preparação para a complexa vida social que aguarda o indivíduo em formação. Por isso, no âmbito escolar, a liberdade de pensamento surge como condição sino qua non da formação cultural, motivo pelo qual a ênfase hegeliana na autonomia das disciplinas curriculares no ginásio desempenha uma função de extrema relevância no processo de formação do indivíduo, já que será o momento de encontro com as ideias e representações que regem a vida pública:

$\mathrm{Na}$ escola calam-se os interesses privados e as paixões do egoísmo; ela é um círculo onde as ocupações giram sobretudo à volta de representações e idéias. [...] O que se realiza na escola, a formação dos indivíduos, é a capacidade dos mesmos para pertencer a essa vida pública (HEGEL, 1994, p. 64). 
A autonomia acarreta necessariamente um conhecimento de si, da realidade e dos outros, ao transportarmos essa perspectiva ao contexto escolar chegaremos a uma compreensão interdisciplinar do currículo, ou seja, a preocupação com a forma em que as disciplinas escolares compreendem-se e compreendem o todo no qual estão inseridas, pois disso depende o cumprir de seu propósito. A escola, na perspectiva de Hegel, não pode ser o lugar de uma ou duas ciências, mas de todas. ${ }^{5}$

Para Hegel, a relação implica na compreensão positiva da contradição, que é algo intrínseco a toda forma de conhecimento. A suprassunção (Aufhebung) descrita em termos educacionais significa que o educando deve aprender a relacionar os diversos saberes proporcionados pelas ciências, apreendendo a transição de um a outro como um processo de progressão científica. Nesse ponto, o método dialético hegeliano, no qual a contradição deve ser considerada e trabalhada, como ele mesmo diz no primeiro volume da Enciclopédia das Ciências Filosóficas em Compêndio (Cf. HEGEL, 1995, p. 163), ocorre como a própria alma motriz do pensamento e da própria ciência, por isso, a educação para ciência implica em um ensino que não é mais estático, pois ocorre por meio de contradições superadas e guardadas, como em um diálogo em que a verdade surge a partir da discussão e das contradições.

Uma proposição não pode se pôr sem se opor a outra em que a primeira é negada, transformada em outra que não ela mesma. Essas proposições se solicitam umas as outras, e, apesar de opostas, tendem a formar uma "unidade de contrários", uma grande síntese (Cf. CIRNE-LIMA, 2003, p. 16). Hegel formula uma educação dialética, na qual, por sua interdependência, nenhuma das disciplinas curriculares pode existir sem estar em diálogo com as demais. Dessa forma, as disciplinas curriculares devem expressar essa estrutura dialógica por meio da interdisciplinaridade.

\footnotetext{
${ }^{5}$ Heráclito, um dos pensadores mais relevantes para a compreensão da dialética hegeliana, reivindica uma formação na qual "Muita instrução não ensina a ter inteligência [...] Pois uma só é a (coisa) sábia, possuir o conhecimento que tudo dirige através de tudo" (HERÁCLITO, 1991, fragmentos 40-41, p. 55), o que expressa bem a crítica hegeliana a uma proposta educacional que busca saber muitas coisas sem saber o necessário: que tudo é um.
} 
Sabe-se que Hegel é um crítico declarado do modelo educacional enciclopédico-iluminista, de certa forma precursor de nossa vertente positivista na educação, por isso declara que o conhecimento das ciências e das artes não pode ocorrer no isolamento, ou na consideração particularizada das ciências, pois isso impossibilitaria sua apreensão do todo, caracterizando aquilo que T. W. Adorno chamou de semiformação (Halbbildung)b, uma formação parcial, unilateral e insuficiente:

Habituamo-nos em demasia a considerar cada arte e ciência particular como algo de específico; aquela a que nos dedicamos apresenta-se como uma natureza que, então, nós possuímos; as outras a que não nos conduzem, nem a nossa destinação nem uma formação anterior [apresentam-se-nos] como algo de estranho, em que a nossa natureza já não consegue penetrar (HEGEL, 1994, p. 44).

Para Hegel, a efetivação da formação cultural está vinculada a aquisição de competências e habilidades ${ }^{7}$ do indivíduo em formação que the permitam apreender o todo da ciência, ou seja, compreender a relação intrínseca existente entre os saberes, o que apenas uma educação interdisciplinar seria capaz de fornecer.

Nos discursos de Hegel a formulação de um modelo de escola impõe uma série de temáticas caras a educação. A compreensão interdisciplinar das disciplinas curriculares proposta denuncia a perspicácia hegeliana na apreensão da realidade educacional de seu tempo, assim como a angústia por possíveis soluções a questões que influenciavam diretamente o cotidiano escolar, cuja necessária formulação impõe-se a alguém que estivesse em uma função como a que exercia

\footnotetext{
6 Segundo Adorno: "Uma semicultura [ou semiformação] que por oposição à simples incultura [ou ausência de formação] hipostasia o saber limitado como verdade, não pode mais suportar a ruptura entre o interior e o exterior, o destino individual e a lei social, a manifestação e a essência. Essa dor encerra, é claro, um elemento de verdade em comparação com a simples aceitação da realidade dada. [...] Contudo a semicultura, em seu modo, recorre estereotipadamente à fórmula que the convém melhor em cada caso, ora para justificar a desgraça, ora para profetizar a catástrofe disfarçada, às vezes, de regeneração." (ADORNO; HORKHEIMER, 1985, p. 183-184).

7 Segundo Perrenoud, as competências são traduzidas em domínios práticos das situações cotidianas que necessariamente passam compreensão da ação empreendida e do uso a que essa ação se destina. Já as habilidades são representadas pelas ações em si, ou seja, pelas ações determinadas pelas competências de forma concreta (Cf. PERRENOUD, 1999, p. 26).
} 
nesse período, legando à escola contemporânea a necessidade de repensar suas bases.

Com sua proposta dialética e interdisciplinar reafirma o ideal da formação cultural, de uma formação integral do indivíduo, que não encontraria na instituição escolar uma mera aglomeração de saberes particulares e desconexos, mas um espaço interdisciplinar capaz de formar um homem culto, apto para tudo (Cf. HEGEL, 1994, p. 44). Porém, a compreensão da sentença "apto para tudo", não implica, na visão de Hegel, a conclusão do processo de formação, indicado mais a realização do ideal proposto pela Fenomenologia do Espírito de uma consciência que efetiva em si o "saber absoluto".

A formação cultural não se encerra na educação institucional da escola, não sendo a formulação de um modelo de escola a realização última da formação humana, que seria assim "necessariamente concretizável" por esse modelo, o que não passa de uma ilusão, como bem ilustra Hegel:

Mas, se o conteúdo objetivo do que se aprende na escola é algo já pronto há muito tempo, em contrapartida, os indivíduos que só agora são formados nesse conteúdo não são ainda algo pronto; não se pode completar totalmente esta atividade preparatória, a formação, mas apenas atingir um determinado nível (HEGEL, 1994, p. 64).

Tal questão salienta a preocupação hegeliana com a pedagogia de seu tempo, tema que o inquietava ainda no prefácio à primeira edição de sua Ciência da Lógica, redigido em 22 de março de 1812, onde critica a miséria dos tempos, que abre mão de uma formação humana em prol de uma educação pragmática e imediata:

Ao encontro dessa doutrina popular - teoria crítica kantiana - veio o clamor da pedagogia moderna - a miséria dos tempos -, que dirige os olhos [apenas] às carências imediatas; segundo a qual, como para o conhecimento a experiência seria o primeiro, assim também para o saber-fazer na vida pública e privada a profundidade teorética seria até mesmo nociva, e o essencial seria o exercício e a formação prática em geral, [para ela] unicamente o que seria aproveitável (HEGEL, 1992, p. 36).

Conhecer apenas o que é útil, sem saber estabelecer qualquer relação desse conhecimento com o mundo da vida, é o oposto da proposta da formação 
cultural. Ela implica em adentrar no mundo da vida no seu sentido mais elevado, ou seja, o conteúdo dessa formação é a própria cultura enquanto linguagem, lazer (estético), trabalho e relações humanas (ética/política). Por isso, esse teor pragmático da educação não pode impor-se como principal objetivo na formação do indivíduo, o que remete a proposta neohumanista assumida pelo filósofo.

Para Hegel, o que importava, tanto na formação ginasial quanto no ensino superior, era transmitir aos jovens o conceito de uma vida completa, o que somente seria possível, em seu entender, nos Studia humaniora. Estudar os clássicos proporcionaria aos educandos, dentre outras vantagens, a necessária ligação da vida pública com a privada, fundamental para apreensão do universal. Os jovens compreenderiam a partir desse estudo que as leis e os deveres não se apresentam como princípios abstratos e sem sentido.

Dessa forma, a formação cultural contrasta com o pragmatismo estreito das orientações pedagógicas que preferiam uma educação para o útil e imediato de uma profissão, em vez de proporcionar ao educando o tesouro inestimável de uma boa cultural geral. Hegel acreditava que uma formação fundada nos clássicos fornece um suporte sólido para a vida pública em todos os seus âmbitos.

Portanto, defende que mesmo a preparação para uma carreira profissional deve ter por fundamento a formação a partir da cultura clássica. Nos clássicos encontramos os elementos iniciais e as representações fundamentais das ciências ou, genericamente, daquilo que é digno de ser conhecido (Cf. HEGEL, 1994, p. 74). Por este motivo, são eles tão apropriados para a preparação destinada às ciências profissionais. Essa indissociável relação da "Bildung hegeliana" e o estudos dos clássicos passa a ser nosso objeto de análise no que segue.

\section{Referências bibliográficas}

ADORNO, T.; HORKHEIMER, M. Dialética do Esclarecimento: fragmentos filosóficos. Tradução. Guido Antonio de Almeida. Rio de. Janeiro: Zahar, 1985.

ALVES, G. L. A produção da escola pública contemporânea. Campinas: Autores Associados, 2005.

CIRNE LIMA, C. R. V. Dialética para principiantes. São Leopoldo: Unisinos, 2003. 
CONDORCET, J.-A.-N. de Caritat, Marquês de. Cinco memórias sobre a educação pública. Tradução de Maria das Graças de Souza. São Paulo: Editora da Unesp, 2008.

HEGEL, G. W. F. Fenomenologia do Espírito - Vol. I. Tradução de Paulo Meneses com colaboração de Karl-Heinz Efken. Petrópolis: Vozes, 2001.

Fenomenologia do Espírito - Vol. II. Tradução de Paulo Meneses com colaboração de Karl-Heinz Efken. 6ª ed. Petrópolis: Vozes, 1992.

Loyola, 2010.

Filosofia do Direito. Tradução de Paulo Meneses, Eł. al. São Paulo: Edições

Enciclopédia das Ciências Filosóficas em Compêndio I: A Ciência da Lógica. Tradução de Paulo Meneses. São Paulo: Loyola, 1995.

Discursos sobre Educação. Tradução de Maria Ermelinda Trindade Fernandes. Lisboa: Edições Colibri, 1994.

Sobre as Maneiras Científicas de Tratar o Direito Natural: seu lugar na filosofia pratica e sua relação com as ciências positivas do direito. Tradução de Agemir Bavaresco e Sergio B. Christino. São Paulo: Edições Loyola, 2007.

HERÁCLITO. Fragmentos. In: PRÉ-SOCRÁTICOS. Fragmentos, doxografia e comentários. Tradução de José Cavalcante de Souza. São Paulo: Nova Cultural, 1991.

HERDER, J. G. Também uma filosofia da história para a formação da humanidade. Tradução portuguesa de Jose M. Justo. Lisboa: Edições Antígona, 1995.

KANT, I. Sobre a pedagogia. Tradução de Francisco C. Fontanella. Piracicaba: Unimep, 1996.

PERRENOUD, P. Construir as competências desde a escola. Porto Alegre: Artes Médicas Sul, 1999.

PERTILLE, J. P. Faculdade do espírito e riqueza material: face e verso do conceito de Vermögen na filosofia de Hegel. Tese. Porto Alegre: Universidade Federal do Rio Grande do Sul, 2005.

YOUNG, M. Para que servem as escolas? In: Educação e Sociedade, Campinas, v. 28, n. 101, set./dez. 2007, p. 1287-1302. 